\title{
Encephalitis associated with autoantibody binding to the anti-N-methyl-D-aspartate receptor: immunopathogenesis, mechanisms, and clinical characteristics
}

\author{
Adhasit Nawa-apisak, Saharat Aungsumart, Metha Apiwattanakul \\ Department of Neurology, Neuroimmunology Unit, Prasat Neurological Institute, Bangkok 10400, Thailand.
}

\section{A B S T R A C T}

Anti-N-methyl-D-aspartate receptor (NMDAR) encephalitis has been increasingly recognized in recent years. This condition may be the most common cause of antibody-mediated encephalitis worldwide. The majority of patients are young at the time of onset, female, and present with an acute-to-subacute onset of behavioral changes followed by seizure, abnormal movement, autonomic dysfunction, and finally hypoventilation with coma if left untreated. The immunopathogenesis of this disease may be due to antibody-mediated internalization of NMDARs from synapses, which results in the dysfunction of particular brain regions (especially the hippocampus and frontostriatal area). Compared to serum, the cerebrospinal fluid permits the more sensitive detection of anti-NMDAR antibody. Ovarian teratoma may be present in up to $40 \%$ of patients but is less frequent in children or late-onset disease (> 45 years old). The severity at the time of disease onset and time to appropriate immunotherapy (high-dose steroid plus plasmapheresis or intravenous immunoglobulin) are independent factors that are associated with good outcomes.

Key words: Abnormal movement; anti-N-methyl-D-aspartate receptors encephalitis; glutamate; immunotherapy; ovarian teratoma; psychiatric symptoms; seizure

\section{INTRODUCTION}

The N-methyl-D-aspartate receptors (NMDAR) are glutamatergic ion channels that are widely expressed in both cortical and subcortical areas of the brain. These receptors are essential in memory and behavior. Hyperactivity of NMDAR may be the underlying mechanism of seizure and some types of dyskinesia, and under activity may be related to schizophrenia. ${ }^{[1]}$

Anti-NMDAR encephalitis has been increasingly recognized in recent years. The exact incidence of anti-NMDAR encephalitis is unknown. Data from a retrospective study indicated that anti-NMDAR encephalitis represented $1 \%$ of all young patients

Corresponding Author: Dr. Metha Apiwattanakul, Department of Neurology, Neuroimmunology Unit, Prasat Neurological Institute 312, Rajavithee Road, Bangkok 10400, Thailand.

E-mail: apiwattanakul.metha@gmail.com

\begin{tabular}{|l|l|}
\hline \multicolumn{3}{|c|}{ Access this article online } \\
\hline Quick Response Code: & Website: \\
\hline & http://nnjournal.net \\
\cline { 2 - 3 } & \\
\hline
\end{tabular}

(aged 18-35 years) who were admitted to an intensive care unit with encephalitis of an unknown etiology (excluding infectious causes). ${ }^{[2]}$ The data obtained from a population-based prospective study in England showed that $4 \%$ of all cases of encephalitis presented anti-NMDAR antibody. ${ }^{[3]}$ In the California Encephalitis Project, ${ }^{[4]}$ anti-NMDAR encephalitis was identified in $4 \%$ of patients $<30$ years of age with encephalitis of an uncertain etiology, and it was detected 4 times more frequently than herpes simplex virus type 1 encephalitis, West Nile virus, or Varicella zoster virus encephalitis. Anti-NMDAR encephalitis was also the most common cause of antibody-mediated encephalitis. There is no information regarding the incidence of anti-NMDAR encephalitis in Asia. However, in Japan, a condition called acute juvenile female nonherpetic encephalitis (AJFNHE) is almost

This is an open access article distributed under the terms of the Creative Commons Attribution-NonCommercial-ShareAlike 3.0 License, which allows others to remix, tweak, and build upon the work non-commercially, as long as the author is credited and the new creations are licensed under the identical terms.

For reprints contact: service@oaepublish.com

Cite this article as: Nawa-apisak A, Aungsumart S, Apiwattanakul $M$. Encephalitis associated with autoantibody binding to the anti-N-methyl-D-aspartate receptor: immunopathogenesis, mechanisms, and clinical characteristics. Neuroimmunol Neuroinflammation 2016;3:79-85.

Received: 21-01-2015; Accepted:13-04-2015 
identical to anti-NMDAR encephalitis. A nationwide survey conducted on AJFNHE showed that the annual incidence was $0.33 / 100,000$ people in Japan. ${ }^{[5]}$ One retrospective study in Thailand reported that anti-NMDAR encephalitis represented $5 \%$ of all cases of encephalitis. ${ }^{[6]}$ Increases in clinical awareness and laboratory availability have led to a rise in the number of diagnoses and case reports, suggesting that the incidence of the disease might be similar to Western countries.

\section{IMMUNOPATHOGENESIS}

Anti-NMDAR antibody can be detected in cerebrospinal fluid (CSF) and/or serum. To be considered pathogenic, the autoantibody should bind to an extracellular antigen (such as an ion channel or neurotransmitter receptor) and cause a functional or structural change. Anti-NMDAR antibody has been shown to bind the NR1 subunit of the NMDAR and reduce the density of NMDARs on the cell membrane. ${ }^{[7]}$ Because NMDARs are protected by the blood-brain barrier (BBB), the antibody somehow enters privileged sites via unknown mechanisms. Disruption of the BBB may be initiated by infection, followed by up-regulation of the major histocompatibility complex or other inflammatory mediators that finally weaken the barrier (some patients develop flu-like symptoms prior to the occurrence of clinical encephalopathy). In some patients, ovarian teratoma is detected at the time of the development of encephalopathy. It has been postulated that the immune response is initiated by this tumor, which expresses NMDAR on its surface. ${ }^{[8]}$ The mechanism underlying immune tolerance is disrupted, potentially by the ectopic expression of NMDARs by the tumor or another mechanism in combination with leakage of the $\mathrm{BBB}$, leading to an attack by the immune system on the NMDAR. ${ }^{[9]}$ It is likely that memory B cells activate T-cells by crossing the BBB and undergoing clonal expansion and differentiation into plasma cells that produce anti-NMDAR. These autoantibodies bind to NMDARs expressed in various areas of the central nervous system and subsequently cause receptor dysfunction.

The acute effect of anti-NMDAR on the NMDAR has been investigated. ${ }^{[10]}$ One study has shown that a decrease in the NMDAR density on the surface of both excitatory and inhibitory hippocampal neurons caused NMDAR hypofunction through immunoglobulin-induced receptor internalization (crosslinking of the receptors). ${ }^{[10]}$ This internalization of receptors resulted in a rapid and selective loss of NMDARs from the neuronal membrane that was titer-dependent and could be reversed after removal of the antibodies. ${ }^{[9]}$ The degree of loss of NMDAR synaptic function may explain the clinical symptoms of patients with this encephalopathy, who initially present with behavioral or cognitive dysfunction with or without seizure, followed by abnormal movements, dysautonomia, and coma with hypoventilation. ${ }^{[11]} \mathrm{A}$ recent study using an animal model of anti-NMDAR encephalitis showed that continuous intraventricular infusion of anti-NMDAR from the CSF of patients with anti-NMDAR encephalitis to mice produced progressive memory deficit, anhedonia, and depressive-like behavior. ${ }^{[12]}$ This correlated with the degree of hippocampal binding by anti-NMDAR and decreases in the density of total and synaptic NMDAR clusters as well as total NMDAR protein concentration. After discontinuation of the infusion, the symptoms improved over the course of a week. The reversal of symptoms correlated with decreased hippocampal bound antibody and restoration of NMDAR levels. ${ }^{[12]}$ The clinical symptoms of the frontostriatal syndrome (psychosis, catatonia, and dystonia) and semi-rhythmic movements may be mainly due to the inactivation of GABAergic neurons as a result of the decreased NMDAR function. This may be explained by the hypofunction of NMDARs, causing the alteration of homeostatic synaptic plasticity to adjust the inhibitory tone in a compensatory direction by down-regulation of inhibitory synapses on excitatory neurons. ${ }^{[10]}$ This decreased function also affects dopaminergic, noradrenergic, and cholinergic pathways, which may explain the autonomic dysfunction and effects on the ponto-medullary respiratory network that lead to hypoventilation. ${ }^{[1]}$

\section{CLINICAL MANIFESTATIONS}

Typical manifestations of anti-NMDAR encephalitis are described as classic symptoms of psychotic or cognitive dysfunction, seizure, abnormal movement, and autonomic dysfunction. The symptoms develop in an acute-to-subacute onset that is usually preceded by prodromal and followed by psychotic features. ${ }^{[13]}$ The spectrum of psychiatric features is varied, and more than one feature can be detected individually. Short-term memory problems are common, but they may be under-detected due to the overwhelming psychotic features. The sequence of symptoms is as follows: seizure, hyperkinetic movement disorders, autonomic instability, and then unresponsiveness with hypoventilation. The seizure may develop early in the course of the disease and usually decreases in frequency with disease progression. ${ }^{[13]}$ After 2-3 weeks, patients who have not been treated develop an unresponsive phase. This clinical presentation of the patient includes mutism, akinetic mutism, and unresponsiveness to verbal commands with eye-opening but the loss of eye contact similar to 
catatonic schizophrenia. These symptoms alternate with periods of agitation. Some patients develop bizarre and inappropriate behavior such as smiling, echophenomenal (both words and movement), or catalepsy-like symptoms. ${ }^{[11]}$ Dissociative (paradoxical) responses to stimuli (unresponsive to painful stimuli, but resistant to eye opening) are often presented in patients, mimicking a psychogenic condition or malingering. Most patients later develop hyperkinetic abnormal movements, the majority of which are oro-lingual-facial dyskinesia; however, other types of movement may also be observed. During the same period, autonomic instability and hypoventilation also occur. The autonomic manifestations include hyperthermia, tachy-bradycardia, and labile blood pressure. Autonomic dysfunction leads to a prolonged cardiac pause and requires a temporary pacemaker. Hypoventilation can present alone or in association with autonomic instability, which necessitates respiratory support. This phenomenon often occurs during the period of hyperkinetic movement, or it can occur during early stages of symptoms. Within 4 weeks of symptom onset, most patients develop a similar spectrum of symptoms irrespective of their age. ${ }^{[14]}$ The characteristics of classical anti-NMDAR encephalitis progression are summarized in Figure 1. However, the clinical presentation of patients with anti-NMDAR encephalitis varies depending on the individual patient. This review focuses on each symptom of anti-NMDAR encephalitis.

\section{Prodromal symptoms}

This viral-like illness usually presents 1-2 weeks before the development of psychiatric symptoms. ${ }^{[13]}$ It is not known whether the symptoms are due to NMDAR dysfunction, the systemic immune response to autoimmune disease or secondary responses to a viral

\section{Clinical spectrum}

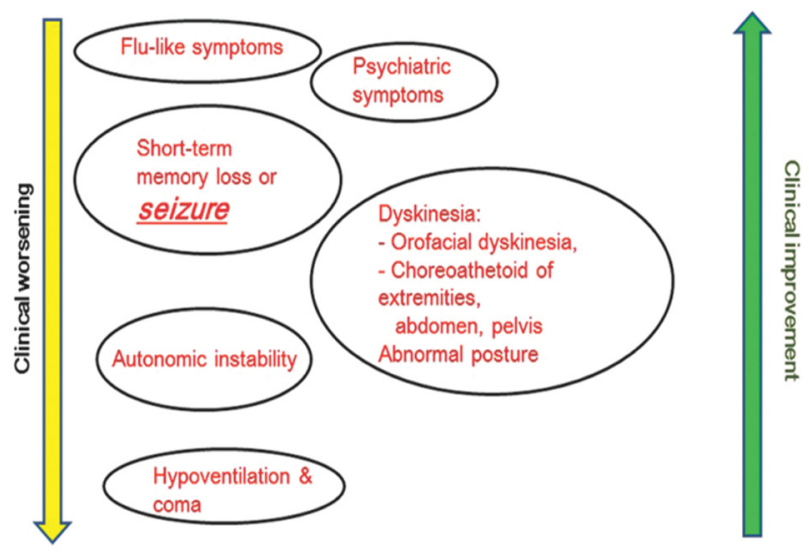

Figure 1: The spectrum of anti- $\mathrm{N}$-methyl-D-aspartate receptor encephalitis showing the common sequence of symptoms with clinical worsening and improvement infection which later precipitate autoimmune disease.

\section{Psychiatric symptoms}

The psychiatric symptoms of anti-NMDAR encephalitis encompass a broad spectrum that includes anxiety, depression, agitation, abnormal behavior, delusion, hallucination, mania, and frank psychosis. ${ }^{[13]}$ The symptoms usually present at the beginning of the disease, leading to medical attention (mostly by a psychiatrist). It is the most common initial manifestation in both sexes. ${ }^{[15]}$ In younger children, parents may describe the symptoms as temper tantrums, behavioral changes, aggression, and progressive speech deterioration. ${ }^{[16]}$ Staff phobia has also been reported in children or adolescents. ${ }^{[16]}$ Overall, the psychiatric symptoms associated with the initial manifestation or during relapses are the same in both sexes and all ages. ${ }^{[17]}$ Isolated psychiatric symptoms can be observed in up to $4 \%$ of patients (either at disease onset or during relapses). ${ }^{[17]}$ These symptoms may be explained by reduced NMDAR synaptic content and disruption of receptor function in discrete regions of the brain. NMDARs are widely expressed throughout the entire brain, and, therefore, the density of receptor expression or the susceptibility of some regions (especially the frontostriatum or hippocampus) to autoantibodies may be the cause of the symptoms. ${ }^{[17]}$

\section{Cognitive dysfunction}

Cognitive dysfunction, especially short-term memory impairment, has been underestimated due to the predominance of psychiatric and speech problems that interfere with the cognitive assessment. ${ }^{[11]}$ There is evidence that IgA antibody subtypes recognizing the NMDAR antibody might be present in patients with progressive cognitive decline. ${ }^{[18]}$ However, a later study suggested that IgA subtypes against NMDAR can be found in the control population and are not related to the neurological disease. ${ }^{[19]}$ The role of NMDAR-IgA remains uncertain.

\section{Seizure}

Seizures occur in approximately $70 \%$ of adults and are even more common in children. ${ }^{[14]}$ They typically occur after a prodromal period and psychiatric symptoms in adults, but they may be the initial manifestation and occur with greater frequency in children and adult males. ${ }^{[15]}$ This phenomenon may be explained by a reduced influence of hormonal factors or by a selection bias whereby women with initial psychiatric symptoms are more likely to be suspected of this disease compared to men. Up to $5 \%$ of patients with anti-NMDAR encephalitis have purely a seizure disorder without prominent neuropsychiatric involvement. ${ }^{[20]}$ The seizure types 
can present as generalized, focal, or complex partial seizures. Some cases may progress to status epilepticus or nonconvulsive status epilepticus. Most of these cases are refractory to treatment with standard antiepileptic drugs but may respond well to immunosuppressive drugs. One case report described nonconvulsive status epilepticus lasting for 6 months that was refractory to all immunomodulating therapies but showed marked improvement following removal of an ovarian tumor. ${ }^{[21]}$ Seizures in anti-NMDAR encephalitic patients usually have an extratemporal origin. ${ }^{[20,22]}$

The most commonly observed (90\%) electroencephalogram (EEG) pattern typically shows diffuse slowing or predominantly anterior slowing, but these phenomena do not correlate with the clinical and MRI findings. ${ }^{[13,16,23]}$ One-third (34\%) of patients exhibited focal slowing. One case series described a unique EEG pattern of "extreme delta brush" in $30 \%$ of the patients in early stages of the disease. This pattern suggests the occurrence of more severe disease (a more prolonged hospitalization). ${ }^{[23]}$

\section{Abnormal movement}

Abnormal movement (mostly hyperkinetic movement) has been described in up to $80 \%$ of patients during the course of the disease and may be the initial manifestation in some patients, especially in the pediatric group. ${ }^{[14]}$ However, abnormal movement usually follows psychiatric symptoms or seizure. Some of these symptoms may be difficult to differentiate from seizure clinically, but the EEG does not reveal electrographic seizure during an episode. ${ }^{[2]}$ These abnormal movements do not respond to anti-epileptic or dopamine receptor antagonist drugs. Abnormal movements can alert clinicians to investigate autoimmune processes in cases of suspected viral encephalitis, which do not typically present this feature. ${ }^{[25,26]}$

Various forms of abnormal movement have been described in anti-NMDAR encephalitis. The majority of these movements are complex uni- or bilateral stereotypic movements, in particular, orofacial dyskinesia. ${ }^{[14,27]}$ The spectrum of abnormal movements includes chorea, choreoathetosis, facial/limb myorhythmia, facial-limb-truncal dystonia, myoclonus, tremor, opsoclonus-myoclonus or ataxia, and opisthotonus. ${ }^{[14,27-29]}$ The distinct abnormal movements observed in anti-NMDAR encephalitis may be due to a dissociated state, in which movement disorder may persist during unconsciousness. ${ }^{[28]}$ This feature may be difficult to differentiate from frontal lobe seizure, but an EEG might provide helpful information. ${ }^{[2]}$ One patient can develop more than one characteristic of abnormal movement during the course of the disease.
MR spectroscopy of the basal ganglia and thalamus may show a reduction of the $\mathrm{N}$-acetylaspartate/creatine (Cr) ratio in patients during involuntary movements. ${ }^{[30]}$

\section{DIAGNOSTIC EVALUATIONS}

The CSF profile in cases of anti-NMDAR encephalitis typically shows pleocytosis and mild protein elevations. The normal CSF profile does not exclude immune-mediated disease. The brain MRI may be normal in up to $50 \%$ of cases. ${ }^{[13]}$ The EEG typically shows diffuse slow or rhythmic activity. The EEG of anti-NMDAR encephalopathy is characterized by an extreme delta brush, which can be found in up to $30 \%$ of cases. ${ }^{[23]}$ For specific antibody testing, it is recommended that both CSF and serum be assessed. In the majority of immune-mediated limbic encephalitis including anti-NMDAR encephalitis, the CSF is more sensitive than the serum, excluding cases of VGKC-complex autoantibody (Lgi1 and Caspr2), in which the serum may be more sensitive than the CSF. ${ }^{[13,31]}$ The NMDAR-IgG can be demonstrated by the presence of immunologic reactivity to mouse brain tissue (especially in the hippocampus area and the granular layer of the cerebellum) or NMDAR-transfected cells [Figure 2]. The antibody titer is higher in the CSF compared to the serum in patients with a poor outcome or the presence of teratoma, and titer changes in the CSF are more likely to be related to clinical relapses than to changes in the serum. ${ }^{[32]}$

Because ovarian teratoma is found in up to $40 \%$ of cases of anti-NMDAR encephalopathy, it is recommended that these patients be screened for this condition. If the initial workup is negative for ovarian teratoma,

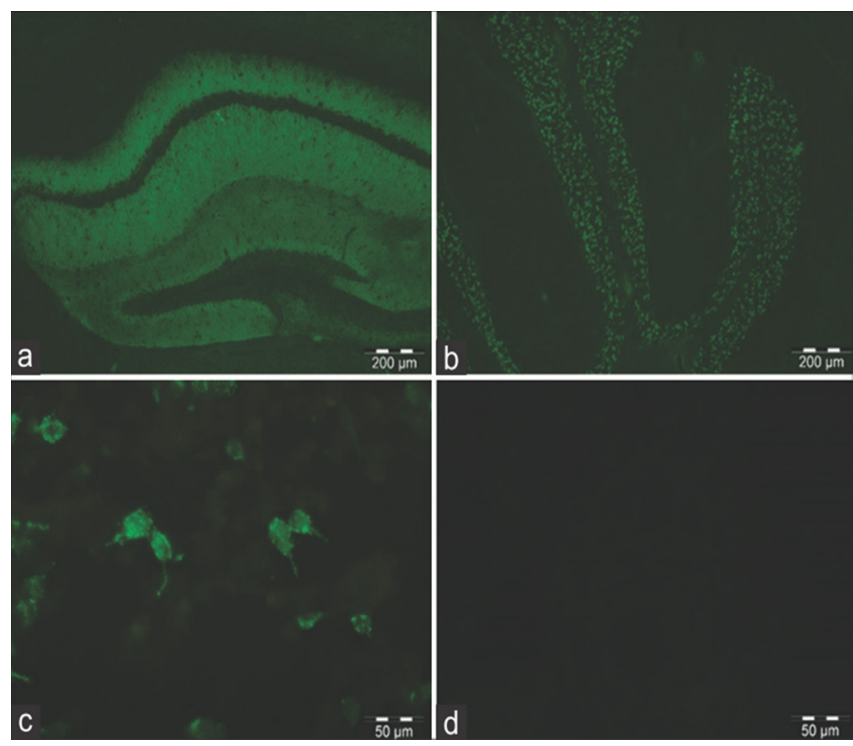

Figure 2: Immunohistochemistry of mouse brain sections showing binding of the N-methyl-D-aspartate receptor (NMDAR)-IgG to the hippocampus. (a) and granular layer of the cerebellum; (b) HEK293 cells expressing NMDAR (GluN1) (c) show antibodies binding to the cell membrane; (d) no reactivity is seen with normal cerebrospinal fluid 
periodic screening for at least 2 years is recommended, even for patients who are in recovery ${ }^{[11]}$ Younger age $(<$ 12 years), older age ( $>40$ years), and male gender are associated with a reduced risk of tumor. ${ }^{[14]}$

\section{TREATMENT, CLINICAL RESPONSE AND RECOVERY}

A large observational cohort study showed that immunotherapy (high-dose steroid plus either plasmapheresis or intravenous immunoglobulin) and tumor removal, if applicable, yielded beneficial neurological outcomes. ${ }^{[14]}$ Patients in whom a tumor was detected and removed within 4 months of disease onset experienced a more complete and rapid recovery than those without tumor. ${ }^{[13]}$ In patients who did not respond to first-line treatment, second-line therapy (cyclophosphamide or rituximab) resulted in improved outcomes and fewer relapses. Two independent predictors of good outcomes were a lower severity of the disease and an earlier time to appropriate treatment. These determining factors are maintained irrespective of the age of disease onset. ${ }^{[14,33]}$ The recovery process is usually the reverse of the clinical presentation. ${ }^{[11]}$ Autonomic and abnormal movement are usually recovered before other symptoms. Psychiatric features may persist up to several months. ${ }^{[13]}$ The anti-NMDAR titer in the CSF usually decreases in parallel to the clinical response, but the presence of antibody may persist for a long period (up to 15 years) despite normal clinical features ${ }^{[34]}$ Clinical history and neurological examination, including a neuropsychiatric test, is the most useful indicator of the treatment response ${ }^{[31]}$ and thus, the periodic detection of the anti-NMDAR titer is not necessary in the context of stable clinical status.

\section{ANTI-NMDAR ENCEPHALITIS IN OLDER AGE}

The onset of anti-NMDAR encephalitis at an age of $>45$ years has some characteristic features that differ from those of young patients. There is a greater frequency of males compared to females (1:1.2), a reduced frequency of tumor association, fewer seizure episodes, and a greater tendency to present with memory deficit in the late-onset group. ${ }^{[33]}$ If tumors are found, then carcinoma is more likely than teratoma. However, within 4 weeks of onset, the patients develop symptoms that are typical of the disease in young adults. The delay in diagnosis and treatment is longer in the late-onset group. This observation may be due to the wide differential diagnosis in clinical presentation. However, other prognostic factors, including an earlier time to treatment, the use of second-line immunotherapy in the case of first-line drug failure, and younger age are associated with improved outcomes.

\section{PREGNANCY AND DISEASE}

There is concern that the anti-NMDAR antibody (subtypes IgG1 and IgG3), which can cross the placenta beginning at 14th week of gestation and up to the time of delivery, ${ }^{[35]}$ may affect the developing brain of the fetus. Factors that may determine outcomes are the gestational age of disease onset, antibody titer of the maternal serum, timing of treatment to deplete maternal pathologic antibody, and the fetal BBB. A few case reports of anti-NMDAR encephalitis during pregnancy showed a positive outcome. ${ }^{[36,37]}$ However, one case report showed evidence for the transplacental transfer of NMDAR antibody ${ }^{[38]}$ The antibody titer in this infant was the same as in the mother at 2 days after delivery and declined until a negative titer was determined at the age of 1 year. The infant showed a delay in global development and had cortical dysplasia. It remains unknown whether these abnormalities resulted from the effect of the transplacental anti-NMDAR antibody or were an indirect effect of the maternal illness.

\section{OVERLAPPING ANTI-NMDAR ENCEPHALITIS AND DEMYELINATING DISEASE}

Many case reports have described the co-existence of anti-NMDAR antibody and demyelinating disease (AQP4-IgG, MOG-IgG). ${ }^{[39]}$ The encephalopathy may precede, follow, or occu simultaneously with a clinical episode of demyelinating disease. Most patients respond to immunotherapy but tend to require more intensive treatment and display more residual deficits. These findings should prompt the awareness of physicians that patients with the demyelinating disease who develop atypical symptoms such as abnormal movements or vice versa should be investigated for other conditions. ${ }^{[39]}$

\section{CONCLUSION}

Anti-NMDAR encephalitis is more common than expected and may be the most common cause of antibody-mediated encephalopathy. This disease should be suspected in children or young adults with acute behavioral problems, seizure, and abnormal movements. Late-onset disease (patients $>45$ years old) may present with memory problems. Investigations of anti-NMDAR antibody or other autoantibodies that are present in the CSF and serum are recommended. Patient outcomes depend on the severity of the disease at the time of onset, early immunotherapy, and adequate second-line drugs if the response to first-line therapy fails. Long-term surveillance of ovarian teratoma in young female patients is prudent if the initial workup is negative. 
Financial support and sponsorship

Nil.

\section{Conflicts of interest}

There are no conflicts of interest.

\section{REFERENCES}

1. Kalia LV, Kalia SK, Salter MW. NMDA receptors in clinical neurology: excitatory times ahead. Lancet Neurol 2008;7:742-55.

2. Pruss H, Dalmau J, Harms L, Holtje M, Ahnert-Hilger G, Borowski K, Stoecker W, Wandinger KP. Retrospective analysis of NMDA receptor antibodies in encephalitis of unknown origin. Neurology 2010;75:1735-9.

3. Granerod J, Ambrose HE, Davies NW, Clewley JP, Walsh AL, Morgan D, Cunningham R, Zuckerman M, Mutton KJ, Solomon T, Ward KN, Lunn MP, Irani SR, Vincent A, Brown DW, Crowcroft NS. Causes of encephalitis and differences in their clinical presentations in England: a multicentre, population-based prospective study. Lancet Infect Dis 2010;10:835-44.

4. Gable MS, Sheriff H, Dalmau J, Tilley DH, Glaser CA. The frequency of autoimmune $\mathrm{N}$-methyl-D-aspartate receptor encephalitis surpasses that of individual viral etiologies in young individuals enrolled in the California Encephalitis Project. Clin Infect Dis 2012;54:899-904.

5. Kamei S, Kuzuhara S, Ishihara M, Morita A, Taira N, Togo M, Matsui M, Ogawa M, Hisanaga K, Mizutani T, Kuno S. Nationwide survey of acute juvenile female non-herpetic encephalitis in Japan: relationship to anti-N-methyl-D-aspartate receptor encephalitis. Intern Med 2009;48:673-9.

6. Saraya A, Mahavihakanont A, Shuangshoti S, Sittidetboripat N, Deesudchit T, Callahan M, Wacharapluesadee S, Wilde H, Hemachudha T. Autoimmune causes of encephalitis syndrome in Thailand: prospective study of 103 patients. BMC Neurol 2013;13:150

7. Dalmau J, Tuzun E, Wu HY, Masjuan J, Rossi JE, Voloschin A, Baehring JM, Shimazaki H, Koide R, King D, Mason W, Sansing LH, Dichter MA, Rosenfeld MR, Lynch DR. Paraneoplastic anti-N-methyl-D-aspartate receptor encephalitis associated with ovarian teratoma. Ann Neurol 2007;61:25-36.

8. Tachibana N, Shirakawa T, Ishii K, Takahashi Y, Tanaka K, Arima $\mathrm{K}$, Yoshida T, Ikeda S. Expression of various glutamate receptors including $\mathrm{N}$-methyl-D-aspartate receptor (NMDAR) in an ovarian teratoma removed from a young woman with anti-NMDAR encephalitis. Intern Med 2010;49:2167-73.

9. Moscato EH, Jain A, Peng X, Hughes EG, Dalmau J, Balice-Gordon RJ. Mechanisms underlying autoimmune synaptic encephalitis leading to disorders of memory, behavior and cognition: insights from molecular, cellular and synaptic studies. Eur $J$ Neurosci 2010;32:298-309.

10. Moscato EH, Peng X, Jain A, Parsons TD, Dalmau J, Balice-Gordon RJ. Acute mechanisms underlying antibody effects in anti-N-methyl-D-aspartate receptor encephalitis. Ann Neurol 2014;76:108-19.

11. Dalmau J, Lancaster E, Martinez-Hernandez E, Rosenfeld MR, Balice-Gordon R. Clinical experience and laboratory investigations in patients with anti-NMDAR encephalitis. Lancet Neurol 2011;10:63-74.

12. Planaguma J, Leypoldt F, Mannara F, Gutierrez-Cuesta J, Martin-Garcia E, Aguilar E, Titulaer MJ, Petit-Pedrol M, Jain A, Balice-Gordon R, Lakadamyali M, Graus F, Maldonado R, Dalmau J. Human $\mathrm{N}$-methyl D-aspartate receptor antibodies alter memory and behaviour in mice. Brain 2015;138:94-109.

13. Dalmau J, Gleichman AJ, Hughes EG, Rossi JE, Peng X, Lai M, Dessain SK, Rosenfeld MR, Balice-Gordon R, Lynch DR. Anti-NMDA-receptor encephalitis: case series and analysis of the effects of antibodies. Lancet Neurol 2008;7:1091-8.

14. Titulaer MJ, McCracken L, Gabilondo I, Armangue T, Glaser C, Iizuka T, Honig LS, Benseler SM, Kawachi I, Martinez-Hernandez E, Aguilar E, Gresa-Arribas N, Ryan-Florance N, Torrents A, Saiz A, Rosenfeld MR, Balice-Gordon R, Graus F, Dalmau J. Treatment and prognostic factors for long-term outcome in patients with anti-NMDA receptor encephalitis: an observational cohort study. Lancet Neurol 2013;12:157-65.

15. Titulaer MJ, Dalmau J. Seizures as first symptom of anti-NMDA receptor encephalitis are more common in men. Neurology 2014;82:550-1.

16. Florance NR, Davis RL, Lam C, Szperka C, Zhou L, Ahmad S, Campen CJ, Moss H, Peter N, Gleichman AJ, Glaser CA, Lynch DR, Rosenfeld MR, Dalmau J. Anti-N-methyl-D-aspartate receptor (NMDAR) encephalitis in children and adolescents. Ann Neurol 2009;66:11-8

17. Kayser MS, Titulaer MJ, Gresa-Arribas N, Dalmau J. Frequency and characteristics of isolated psychiatric episodes in anti-N-methyl-d-aspartate receptor encephalitis. JAMA Neurol 2013;70:1133-9

18. Pruss H, Holtje M, Maier N, Gomez A, Buchert R, Harms L, Ahnert-Hilger G, Schmitz D, Terborg C, Kopp U, Klingbeil C, Probst C, Kohler S, Schwab JM, Stoecker W, Dalmau J, Wandinger KP. IgA NMDA receptor antibodies are markers of synaptic immunity in slow cognitive impairment. Neurology 2012;78:1743-53.

19. Dahm L, Ott C, Steiner J, Stepniak B, Teegen B, Saschenbrecker S, Hammer C, Borowski K, Begemann M, Lemke S, Rentzsch K, Probst C, Martens H, Wienands J, Spalletta G, Weissenborn K, Stocker W, Ehrenreich H. Seroprevalence of autoantibodies against brain antigens in health and disease. Ann Neurol 2014;76:82-94.

20. Irani SR, Bien CG, Lang B. Autoimmune epilepsies. Curr Opin Neurol 2011;24:146-53.

21. Johnson N, Henry C, Fessler AJ, Dalmau J. Anti-NMDA receptor encephalitis causing prolonged nonconvulsive status epilepticus. Neurology 2010;75:1480-2.

22. Niehusmann P, Dalmau J, Rudlowski C, Vincent A, Elger CE, Rossi JE, Bien CG. Diagnostic value of N-methyl-D-aspartate receptor antibodies in women with new-onset epilepsy. Arch Neurol 2009;66:458-64.

23. Schmitt SE, Pargeon K, Frechette ES, Hirsch LJ, Dalmau J, Friedman D. Extreme delta brush: a unique EEG pattern in adults with anti-NMDA receptor encephalitis. Neurology 2012;79:1094-100.

24. Irani SR, Bera K, Waters P, Zuliani L, Maxwell S, Zandi MS, Friese MA, Galea I, Kullmann DM, Beeson D, Lang B, Bien CG, Vincent A. $\mathrm{N}$-methyl-D-aspartate antibody encephalitis: temporal progression of clinical and paraclinical observations in a predominantly non-paraneoplastic disorder of both sexes. Brain 2010;133:1655-67.

25. TitulaerMJ,LeypoldtF,DalmauJ. Antibodies to N-methyl-D-aspartate and other synaptic receptors in choreoathetosis and relapsing symptoms post-herpes virus encephalitis. Mov Disord 2014;29:3-6.

26. Pruss H, Finke C, Holtje M, Hofmann J, Klingbeil C, Probst C, Borowski K, Ahnert-Hilger G, Harms L, Schwab JM, Ploner CJ, Komorowski L, Stoecker W, Dalmau J, Wandinger KP. $\mathrm{N}$-methyl-D-aspartate receptor antibodies in herpes simplex encephalitis. Ann Neurol 2012;72:902-11.

27. Baizabal-Carvallo JF, Stocco A, Muscal E, Jankovic J. The spectrum of movement disorders in children with anti-NMDA receptor encephalitis. Mov Disord 2013;28:543-7.

28. Stamelou M, Plazzi G, Lugaresi E, Edwards MJ, Bhatia KP. The distinct movement disorder in anti-NMDA receptor encephalitis may be related to status dissociatus: a hypothesis. Mov Disord 2012;27:1360-3.

29. Smith JH, Dhamija R, Moseley BD, Sandroni P, Lucchinetti $\mathrm{CF}$, Lennon VA, Kantarci OH. N-methyl-D-aspartate receptor autoimmune encephalitis presenting with opsoclonus-myoclonus: treatment response to plasmapheresis. Arch Neurol 2011;68:1069-72.

30. Kataoka H, Dalmau J, Taoka T, Ueno S. Reduced N-acetylaspartate in the basal ganglia of a patient with anti-NMDA receptor encephalitis. Mov Disord 2009;24:784-6.

31. McKeon A, Lennon VA. NMDAR encephalitis: which specimens, and the value of values. Lancet Neurol 2014;13:133-5.

32. Gresa-Arribas N, Titulaer MJ, Torrents A, Aguilar E, McCracken L, Leypoldt F, Gleichman AJ, Balice-Gordon R, Rosenfeld MR, Lynch D, Graus F, Dalmau J. Antibody titres at diagnosis and during follow-up of anti-NMDA receptor encephalitis: a retrospective study. Lancet Neurol 2014;13:167-77.

33. Titulaer MJ, McCracken L, Gabilondo I, Iizuka T, Kawach 
I, Bataller L, Torrents A, Rosenfeld MR, Balice-Gordon R, Graus F, Dalmau J. Late-onset anti-NMDA receptor encephalitis. Neurology 2013;81:1058-63.

34. Hansen HC, Klingbeil C, Dalmau J, Li W, Weissbrich B, Wandinger KP. Persistent intrathecal antibody synthesis 15 years after recovering from anti-N-methyl-D-aspartate receptor encephalitis. JAMA Neurol 2013;70:117-9.

35. Hoftman AC, Hernandez MI, Lee KW, Stiehm ER. Newborn illnesses caused by transplacental antibodies. Adv Pediatr 2008;55:271-304.

36. Kumar MA, Jain A, Dechant VE, Saito T, Rafael T, Aizawa H, Dysart KC, Katayama T, Ito Y, Araki N, Abe T, Balice-Gordon R, Dalmau J. Anti-N-methyl-D-aspartate receptor encephalitis during pregnancy. Arch Neurol 2010;67:884-7.
37. McCarthy A, Dineen J, McKenna P, Keogan M, Sheehan J, Lynch T, O'Rourke K. Anti-NMDA receptor encephalitis with associated catatonia during pregnancy. J Neurol 2012;259:2632-5

38. Jagota P, Vincent A, Bhidayasiri R. Transplacental transfer of NMDA receptor antibodies in an infant with cortical dysplasia. Neurology 2014;82:1662-3.

39. Titulaer MJ, Hoftberger R, lizuka T, Leypoldt F, McCracken L, Cellucci T, Benson LA, Shu H, Irioka T, Hirano M, Singh G, Cobo Calvo A, Kaida K, Morales PS, Wirtz PW, Yamamoto T, Reindl M, Rosenfeld MR, Graus F, Saiz A, Dalmau J. Overlapping demyelinating syndromes and anti-N-methyl-D-aspartate receptor encephalitis. Ann Neurol 2014;75:411-28. 